\title{
Use of Tissue Oxygen Saturation Levels as a Vital Sign in the ED Triage
}

Sadiye Yolcu ${ }^{1}$, Adem Kaya ${ }^{1}$

${ }^{1}$ Adana City Research and Education Hospital Dept. of Emergency Medicine, Adana, Turkey

\section{Correspondence:}

Sadiye Yolcu

Address: Adana City Research and Education Hospital Dept. of Emergency Medicine, Adana, Turkey

Email: sadiyeyolcu@yahoo.com

Received: 27.03.2019,

Accepted: 30.05.2019

https://doi.org/10.5799/jcei/5832

\begin{abstract}
Objectives: The utilization of vital signs as triage tools remains a mainstay ofemergency patients. The evolution of monitoring technologies, including the noninvasive tissue oxygen saturation devices has improved our ability to monitor the critically ill patients. The aim of the present study was to determine the tissue oxygen saturation (StO2) levels of the patients as a vital sign during emergency triage.

Methods: Approximately 30-35 patients present to our emergency department each day and the triage of these patients are performed by a nurse at admission time. A three level system (1: red, 2: yellow, 3: green) is used to determine the triage level of the patients presenting to our department. We examined 150 patients during five days. Age gender, triage levels and hospitalization status of the patients were noted. For the $\mathrm{StO}_{2}$ level measurement, an Inspectra device was placed to the right thenar muscle for $10 \mathrm{~s}$ and mean of the first, fifth and 10th second values were noted at the admission time.

Results: In our study 73 females (48.6\%), 77 males (51.4\%) totally 150 patients were included. We determined a significant difference between green and yellow $(p=0.00)$, green and red $(p=0.00)$, yellow and red $(p=0.001)$ according to $\mathrm{StO}_{2}$ levels. We couldn't find a significant difference between females and males in triage groups ( $p=0.13$ for green, $p=0.71$ for yellow, $p=0.86$ for red). There was correlation between $\mathrm{StO}_{2}$ - triage level $(p=0.00, r=0.609)$ and $\mathrm{StO}_{2-}$ hospitalization status $(p=0.00, r=0.449)$.
\end{abstract}

Conclusion: StO2 level measurement may be helpful in determining the triage level of the patients presenting to the ED.

Keywords: emergency, tissue oxygen saturation, triage

\section{INTRODUCTION}

Emergency departments (ED) have to consider new and effective methods to promptly identify and treat the critically ill or potentially critically ill patients because of dramatic increases in patient volumes. Rapid identification of critically ill patients could be imperative for the outcome [1]. Most of the current triage tools in use are based on a categorical measurement acuity scale $[2,3]$. In practice, the use of a rapid triage system within an ED diminished the time period of arrival-to-triage and improved throughput of the nonurgent patient [4]. The clinical assessment of patients in the ED is based in part upon the measurement and interpretation of initial vital signs. Emergency physicians and nurses usually use vital signs as markers of the severe illness, determining triage categories and directing more immediate attention to those patients with abnormal vital signs [5].

Monitoring of early regional ischemia may be more helpful to provide early intervention given that an ischemic injury is reversible. Continuous and noninvasive techniques for tissue ischemia monitoring have been studied recently but there is a limited data in literature. Lack of agreement between bioimpedance and continuous thermodilution measurement of cardiac output in intensive care unit patients [6]. Physicians have been used near-infrared spectroscopy (NIRS) device for hypoxemia and ischemia which permits noninvasive, continuous monitoring of tissue 
StO2 in Triage

\begin{tabular}{|c|c|c|c|c|c|c|}
\hline & \multicolumn{2}{|c|}{ Green (n:58, 38.7\%) } & \multicolumn{2}{|c|}{ Yellow (n:43, 28.6\%) } & \multicolumn{2}{|c|}{ Red (n:49, 32.7\%) } \\
\hline & $\mathrm{F}(\mathrm{n}: 35,47.9 \%)$ & $M(n: 23,29.9 \%)$ & $F(n: 18,24.7 \%)$ & $M(n: 25,32.5 \%)$ & $F(20,27.4 \%)$ & $M(n: 29,37.7 \%)$ \\
\hline Age & $\begin{array}{c}29.14 \pm 13.84 \\
(\min : 18, \max : 65)\end{array}$ & $\begin{array}{c}37.47 \pm 16.57 \\
(\min : 23, \max : 70)\end{array}$ & $\begin{array}{c}54.72 \pm 13.21 \\
(\min : 40, \max : 75)\end{array}$ & $\begin{array}{c}53.04 \pm 16.95 \\
(\min : 18, \max : 75)\end{array}$ & $\begin{array}{c}57.90 \pm 15.87 \\
(\min : 18, \max : 75)\end{array}$ & $\begin{array}{c}56.03 \pm 14.65 \\
(\min : 22, \max : 80)\end{array}$ \\
\hline $\mathrm{StO}_{2}(\%)$ & $\begin{array}{c}74.69 \pm 1.54 \\
(\min : 70, \max : 76)\end{array}$ & $\begin{array}{c}76,09 \pm 2.64 \\
(\min : 72, \max : 80)\end{array}$ & $\begin{array}{c}80 \pm 5.15 \\
(\min : 73, \max : 87)\end{array}$ & $\begin{array}{c}79.88 \pm 4.04 \\
(\min : 75, \max : 87)\end{array}$ & $\begin{array}{c}83.15 \pm 8.67 \\
(\min : 62, \max : 93)\end{array}$ & $\begin{array}{c}82.76 \pm 7.16 \\
(\min : 67, \max : 92)\end{array}$ \\
\hline \multicolumn{7}{|l|}{ Hospitalization } \\
\hline $\begin{array}{c}\text { Discharged } \\
(\mathrm{n}: 102,68 \%)\end{array}$ & \multicolumn{2}{|c|}{$\mathrm{n}: 58(100 \%)$} & \multicolumn{2}{|c|}{$35(81.4 \%)$} & \multicolumn{2}{|c|}{$9(18.4 \%)$} \\
\hline $\begin{array}{c}\text { Hospitalized into } \\
\text { service } \\
\text { (n:17, 11.3\%) }\end{array}$ & \multicolumn{2}{|c|}{$\mathrm{n}: 0(0 \%)$} & \multicolumn{2}{|c|}{$8(18.6 \%)$} & \multicolumn{2}{|c|}{$9(18.4 \%)$} \\
\hline $\begin{array}{l}\text { Hospitalized into ICU } \\
(n: 31,20.7 \%)\end{array}$ & \multicolumn{2}{|c|}{$\mathrm{n}: 0(0 \%)$} & \multicolumn{2}{|c|}{$0(\%)$} & \multicolumn{2}{|c|}{31 (63.3\%) } \\
\hline
\end{tabular}

hemoglobin oxygen saturation $(\mathrm{StO} 2)$ in muscle $[7,8]$. At the beginning, it had been used by neurologists and neurosurgeons just for brain and other large organs $[9,10]$. NIRS has also been used in critically ill patients especially in intensive care units and studies about NIRS have still been going on for its efficacy and new fields for its usage [11-13]. Near-infrared spectroscopy (NIRS) provides noninvasive measurement of $\mathrm{StO}_{2}$ within the microcirculation [14]. NIRS has also been used to determine the severity of hemorrhagic shock, as a guide for fluid resuscitation, in septic shock, and predicting multiple-organ dysfunction syndrome $[8,9,15,16]$.

However, data is limited about the $\mathrm{Sto}_{2}$ levels as a vital sign in triage among patients presenting to ED [17-19].

Aim: The aim of the present study was to determine the $\mathrm{StO} 2$ levels of the patients as a vital sign during emergency triage.

\section{METHODS}

Approximately 30-35 patients present to our emergency department each day and the triage of these patients are performed by a nurse at the arrival time. A three level system (1:red (emergency), 2:yellow (urgent), 3:green (nonurgent)) is used to determine the triage level of the patients presenting to our department. The diagnoses of the patients were not used in the study, we just wanted to determine the $\mathrm{StO}_{2}$ levels according to the triage level. For this study approval of the Human Study Committee of our medical faculty was provided. The participants/relatives were informed and gave their informed consent. We examined 150 patients during five days. Age gender, triage levels and hospitalization status of the patients were noted. For the $\mathrm{StO}_{2}$ level measurement, an Inspectra device was placed to the right thenar muscle for $10 \mathrm{~s}$ and mean of the first, fifth and 10th second values were noted at the admission time. In our study, we measured thenar muscle $\mathrm{StO}_{2}$ via NIRS (InSpectra; Hutchinson Technology). Cardiopulmonary arrest patients and patients under 18 age were excluded from the study.

\section{Statistical Analysis}

The normal distribution and homogeneity of each parameter were tested using the Shapiro-Wilk test and the Kolmogorov-Smirnov test. Age and $\mathrm{STO}_{2}$ values did not suit the normal distribution. A Mann Whitney-U test was used for differences between triage level groups. A Spearman correlation test was used for correlation analysis. In all tests the significance level was $\mathrm{p}<0.05$. SPSS (Statistical Package for the Social Sciences) software 20.0 was used for analysis.

\section{RESULTS}

In our study 73 females (48.6\%), 77 males (51.4\%) totally 150 patients were included. The mean age of our study group was $46.50 \pm 18.89$ (min:18, max:80). Mean age of the females was $43.32 \pm 19.68$ (min:18, max:75). Mean age of males was $49.51 \pm 5.80$ (min:67, max:92). Mean $\mathrm{StO}_{2}$ levels of triage groups were $75.24 \pm 2.14$ (min:70, max:80) for green, $79.93 \pm 4.48$ (min:73, max:87) for yellow, $82.92 \pm 7.73$ (min:62, max:93) for red triage categories. Detailed age, $\mathrm{StO}_{2}$ levels and hospitalization status of the groups according to gender is given in Table 1. We determined a significant difference between green and yellow $(\mathrm{p}=0.00)$, green and red $(\mathrm{p}=0.00)$, yellow and red $(\mathrm{p}=0.001)$ according to $\mathrm{StO}_{2}$ levels. We couldn't find a significant difference between females and males in triage groups $(\mathrm{p}=0.13$ for green, $\mathrm{p}=0.71$ for yellow, $\mathrm{p}=0.86$ for red). There was correlation between $\mathrm{StO}_{2}$ - triage level $(\mathrm{p}=0.00, \mathrm{r}=0.609)$ and $\mathrm{StO}_{2}$-hospitalization status $(\mathrm{p}=0.00, \mathrm{r}=0.449)$.

\section{DISCUSSION}

In our study, we determined a significant difference between green and yellow, green and red, yellow and red according to $\mathrm{StO}_{2}$ levels. But we couldn't find a significant difference between females and males in triage groups. There was correlation between $\mathrm{StO}_{2}$ - triage level and $\mathrm{StO}_{2}$ hospitalization status. Patients with elevated StO2 levels were hospitalized into a clinic and ICU.

Sagraves et al. investigated the Hutchinson Technologies' InSpectra STO2 monitor in the prehospital arena with respect to ease of use by emergency providers to correlate STO2 measurements with patient outcomes. In their study, 
they included 48 patients and compared the average Injury Severity Score (ISS), hospitalization status including hospitalization day and StO2 levels. They reported that STO2 endpoints were significantly different between patient groups having an ISS $<25$ versus ISS $>25$. STO 2 endpoints were not related with Glasgow Coma Scale, ventilator days, ICU days, or hospital days. In that study, first and endpoint StO2 levels were significantly different between survivors and non-survivors. They reported that the measurement of STO2 in the field is easy and the NIRS technology holds the potential to be a resuscitative adjunct with the ultimate goal to allow emergency personnel to have a non-invasive monitor of hypoperfusion in the field and the early detection of resuscitation need during post-injury period [20].

Similarly, Guyette investigated whether prehospital tissue oximetric values could predict the need for in-hospital LSI (life saving interventions), defined as the need for emergent operation or emergent transfusion in the first 24 hours of hospitalization. They applied the StO2 device in a convenience sample of 150 trauma patients transported by a single critical care transport service. They measured StO2, deoxygenation and reoxygenation levels of the patients. In their study the initial mean StO2 level was 78. Prehospital deoxygenation was associated with need for LSI in their study population. Guyette reported that further studies of deoxygenation were needed for determining whether it could be used as a triage criterion or an endpoint for resuscitation [21].

Contraversial to our study, Bazerbashi et al. suggested that low StO2 levels predict the intensive care unit admission. They studied in 158 cancer patients (a specific patient group). It may show that $\mathrm{StO} 2$ levels may have a range similar to $\mathrm{Ph}$. Further studies are warranted to determine the limits. In our study, similar to Bazerbashi's study there were values under 70 and those were admitted to the intensive care unit via red level. But this didn't change the statistics. They ve suggested that tissue oxygen saturation at triage identifies critical patients who may not be recognized by vital signs alone and issue oxygen saturation measurement could help providers make earlier decisions regarding hospital resource allocation [17].

NIRS was used to determine whether NIRS-derived StO2 measures (StO2 initial, $\mathrm{StO} 2$ occlusion and $\mathrm{StO} 2$ recovery) identify patients who are in shock and at increased risk of organ dysfunction (Sequential Organ Failure Assessment (SOFA) score $\geq 2$ at 24 hours) and dying in the hospital. This prospective study had been perfomed in $168 \mathrm{ED}$ patients. According to the results NIRS measurements for the StO2 initial, StO2 occlusion and $\mathrm{StO} 2$ recovery slope were abnormal in patients with septic shock compared to sepsis patients [22]. Martin et al. hypothesized that NIRS derived StO2 could assist in identifying shock in 115 casualties arriving to a combat support hospital and predict the need for life-saving interventions (LSIs) and blood transfusions. They included 147 combat casualties. In their study, NIRSderived StO2 obtained on arrival predicts the need for blood transfusion in casualties who initially seem to be hemodynamically stable (SBP >90) [23].

\section{CONCLUSION}

$\mathrm{StO} 2$ level measurement is an easy noninvasive technique and this method may be used as a vital sign and may be helpful in determining the triage level of the patients presenting to the ED. Further comprehensive studies are warranted on $\mathrm{StO} 2$ usage especially in five level triage ED systems.

Declaration of interest: The authors report no conflicts of interest.

Financial Disclosure: No financial support was received.

\section{REFERENCES}

1. Howard A, Brenner GD, Drexler J. Improving the Prompt Identification of the Emergency Severity Index Level 2 Patient in Triage: Rapid Triage and the Registered Nurse Greeter. J Emerg Nurs. 2014 Apr 15. doi: 10.1016/j.jen.2014.01.009

2. Standards Committee Council, 1994. National Triage Scale. Emerg. Med. 6:145-146.

3. Beveridge R. CAEP issues The Canadian Triage and Acuity Scale: a new and critical element in health care reform. Canadian Association of Emergency Physician. J. Emerg. Med. 1998;16:507-511.

4. Doyle SL, Kingsnorth J, Guzzetta CE. Outcomes of implementing rapid triage in the pediatric emergency department. J Emerg Nurs. 2012;38(1):30-5.

5. Cooper RJ, Schriger DL, Flaherty HL. Effect of vital signs ontriage decisions. Ann Emerg Med. 2002;39(3):223232.

6. Imhoff M, Lehner JH, Lohlein D. Noninvasive wholebody electrical bioimpedance cardiac output and invasive thermodilution cardiac output in high-risk surgical patients Crit Care Med 2000;28(8):2812-8.

7. Logemann F, Gras C, Mehler D, et al. Bilateral monitoring of cerebral oxygen saturation in aortic arch surgery. Anasthesiol Intensivmed Notfallmed Schmerzther 2001;36(6):388.

8. Fukui D, Urayama $H$, Tanaka $K$, et al. Use of nearinfrared spectroscopic measurement at the buttocks during abdominal aortic surgery. Circ J 2002;66(12):1128-31.

9. de Letter JA, Sie HT, Thomas BM, et al. Near-infrared reflected spectroscopy and electroencephalography during carotid endarterectomy: In search of a new shunt criterion. Neurol Res 1998;20(suppl 1):S23-7

10. Calderon-Arnulphi M, Alaraj A, Slavin KV. Near infrared technology in neuroscience: past, present and future. Neurol Res 2009;31(6):605-14. 
11. Crookes BA, Cohn SM, Bloch S, et al. Can near-infrared spectroscopy identify the severity of shock in trauma patients? J Trauma 2005;58(4):806-13.

12. Moore FA, Nelson T, McKinley BA, et al. Massive transfusion in trauma patients: tissue hemoglobin oxygen saturation predicts poor outcome. J Trauma 2008;64(4):1010-23.

13. Beilman GJ, Groehler KE, Lazaron V, et al. Nearinfrared spectroscopy measurement of regional tissue oxyhemoglobin saturation during hemorrhagic shock. Shock 1999;12(3):196-200.

14. Cohn SM. Near-infrared spectroscopy: potential clinical benefits in surgery. J Am Coll Surg 2007;205:322.

15. Beilman GJ, Blondet JJ. Near-infrared spectroscopyderived tissue oxygen saturation in battlefield injuries: a case series report. World J Emerg Surg 2009;4:25.

16. George ME, Beilman GJ, Mulier KE. Noninvasive tissue oxygen saturation measurements identify supply dependency. J Surg Res 2010;160:40.

17. Bazerbashi H, Merriman KW, Toale KM. Low tissue oxygen saturation at emergency center triage is predictive of intensive care unit admission. J Crit Care. 2014 Oct;29(5):775-9. doi: 10.1016/j.jcrc.2014.05.006. Epub 2014 May 27.

18. Cohn SM, Nathens AB, Moore FA. Tissue oxygen saturation predicts the development of organ dysfunction during traumatic shock resuscitation. J Trauma 2007;62:44. Discussion.

19. Yolcu S, Erdur B. Use of tissue oxygenation (StO2) monitor in the ED. Am J Emerg Med. 2014. doi: 10.1016/j.ajem.2014.04.037.

20. Sagraves SG, Newell MA, Bard MR. Tissue oxygenation monitoring in the field: a new EMS vital sign. J Trauma. 2009 Sep;67(3):441-3.

21. Guyette FX, Gomez H, Suffoletto B. Prehospital dynamic tissue oxygen saturation response predicts inhospital lifesaving interventions in trauma patients. J Trauma Acute Care Surg. 2012 Apr;72(4):930-5.

22. Shapiro NI, Arnold R, Sherwin R. Emergency Medicine Shock Research Network (EMShockNet). The association of near-infrared spectroscopy-derived tissue oxygenation measurements with sepsis syndromes, organ dysfunction and mortality in emergency department patients with sepsis. Crit Care. 2011;15(5):R223. doi: 10.1186/cc10463. Epub 2011 Sep 22.

23. Beekley AC, Martin MJ, Nelson T. Continuous noninvasive tissue oximetry in the early evaluation of the combat casualty: a prospective study. J Trauma. 2010 Jul;69 Suppl 1:S14-25. doi: 10.1097/TA.0b013e3181e42326.9. 